\title{
Effect of Acetic Acid and Citric Acid Modification on Biodegradability of Cassava starch Nanocomposite
}

\section{Films}

\author{
AbdulRasheed-Adeleke Tawakaltu $^{1 *}$, E. C. Egwim ${ }^{1}$, S. S. Ochigbo ${ }^{2}$ and P. C. Ossai ${ }^{1}$ \\ 1. Department of Biochemistry, Federal University of Technology Minna, Niger State, Nigeria \\ 2. Department of Chemistry, Federal University of Technology Minna, Niger State, Nigeria
}

\begin{abstract}
The effect of acetic acid and citric acid modification of cassava starch on the biodegradability of their films reinforced with lignin and nanofiber was determined. Cassava starch was first modified with acetic anhydride and citric acid, characterized, filled with lignin and nanofiber to produce the films. Biodegradation studies were based on determinations of water absorption capacity, soil burial, enzyme degradation and reducing sugar (glucose). Results showed that great variations in water absorption capacities, weight loss in soil, enzyme degradation and reducing sugar were observed with TPS (Thermoplastic starch) having the fasted and highest water uptake, weight loss in soil, enzyme degradation and glucose equivalents while the modified starches had the slowest and least values compared with the native starch. Thus, acetic anhydride and citric acid modification improved the cross linking of the native starch thereby making it less biodegradable but not affecting its overall biodegradability.
\end{abstract}

Key words: Biodegradation, water absorption, reducing sugar, modification, cassava starch, lignin, TPS (Thermoplastic starch).

\section{Introduction}

The blooming use of synthetic polymer materials has brought about a great deal of environmental problems despite their merits. Solid waste originating from these materials is a major contributor to environmental pollution because it is non-biodegradable. Moreover, these synthetic polymers usually originate from products of petroleum and are non-biodegradable. In order to overcome this grave problem, more attention is now being shifted to alternative polymer materials that are biodegradable.

Natural polymers have attracted greater attention because they are inherently biodegradable [1]. Among the natural polymers, starch and cellulose are of prime interest due to their complete biodegradability [2], availability from many plants [3], cost effectiveness and renewability [4]. Likewise, cellulose has

"Corresponding author: AbdulRasheed-Adeleke Tawakaltu, Ph.D. student, research field: biochemistry. substantial stiffness, desired mechanical features and thermal recyclability by combustion. Besides, the low density of cellulose results in particular mechanical properties [5].

If cellulose fibers combine with thermoplastic matrix, immense difficulty regarding incompatibility between polar and hydrophilic fibers and non-polar and hydrophobic matrix will result. Thus, in order to improve matrix reinforcement adhesion in composites, starch or the surface of cellulose can be physically or chemically modified. The modification can be carried out by acetylation and alkali treatment [6].

In this study, native cassava starch was modified with acetic anhydride and citric acid.

\section{Methodology}

\subsection{Materials}

Cassava tubers (Manihot esculenta) were purchased from the local farm of Minna, Niger State while bamboo stems (Bambusa vulgaris) 
were collected from the Izom forest in Gurara, Niger State. Analytical grades of glycerol, ethanol, acetic anhydride $\left.\left(\mathrm{CH}_{3} \mathrm{CO}\right)_{2} \mathrm{O}\right)$, citric acid, sodium hydroxide, hydrochloric acid, sulphuric acid, hydrogen peroxide, glucose, dinitrosalicylic acid, sodium acetate, acetic acid, $\alpha$-amylase and cellulase were purchased.

\subsection{Starch Modification}

Cassava starch was modified with acetic anhydride, citric acid and dual modification with acetic anhydride and citric acid as described by Aning [7], Chowdary and Enturi [8] and Veerreddy et al. [9].

\section{Characerization of Modified Starch}

\subsection{Starch $P H$}

Two grams ( $2 \mathrm{~g}$ ) of starch was dispersed in $20 \mathrm{ml}$ of distilled water in a $50 \mathrm{ml}$ beaker for $1 \mathrm{~h}$ at room temperature. The $\mathrm{pH}$ was, thereafter, measured using a $\mathrm{pH}$ meter.
3.2 Determination of Acetyl/Carboxyl Content and Degree of Substitution (DS)

The percent acetylation/carboxylation and DS were determined titrimetrically as described by Aning [7]. One gram of acetylated cassava starch sample/or starch citrate sample were suspended in $50 \mathrm{ml}$ of a $75 \%$ ethanol solution. The slurry was kept in a water bath at $50{ }^{\circ} \mathrm{C}$ for 30 min with constant stirring. The slurry was then cooled at room temperature and $40 \mathrm{~mL}$ of $0.5 \mathrm{M}$ potassium hydroxide was added. The slurry was allowed to stand for $72 \mathrm{~h}$ at room temperature with occasional swirling. The excess alkali was titrated with $0.5 \mathrm{M}$ hydrochloric acid using phenolphthalein as an indicator. The solution was allowed to stand for another $2 \mathrm{~h}$. Any additional alkali that might leach from the sample was titrated. Blank with native starch was analysed concurrently. The sample volume, the hydrochloric acid normality and the volume of hydrochloric acid required to titrate the blank and sample were recorded. Duplicate measurements were performed for each starch sample [7].

$\%$ Acetylation $/$ carboxylation $=[\mathrm{ml}($ blank $)-\mathrm{ml}($ sample $)]$ x normality of acid $\times 0.043 \times 100$

Weight of the sample, $g$ (dry basis)

Degree of substitution (DS) $=162 \times \%$ acetylation/carboxylation

$$
4300-(42 \times \% \text { acetylation/carboxylation })
$$

\subsection{Film Production}

Nanocomposite films containing fillers (bamboo lignin and bamboo nanofiber) were prepared by casting method. Then nanocomposites were prepared from $100 \mathrm{wt} \%$ native and modified cassava starch, containing $5 \mathrm{wt} \%$ fillers and $50 \mathrm{wt} \%$ plasticizer (glycerol) and 50\% (w/v) water. The solutions were prepared by heating the material over a magnetic stirrer at $70 \pm 2{ }^{\circ} \mathrm{C}$ and medium stirring rate for $15 \mathrm{~min}$. The mixtures were then poured into petri dishes and oven-dried at $50{ }^{\circ} \mathrm{C}$ for $24 \mathrm{~h}$ to obtain the films.

\subsection{Water Absorption Test}

Pieces of the films were first oven-dried at $50{ }^{\circ} \mathrm{C}$ for
$24 \mathrm{~h}$ after which, samples were weighed for the dry weight, and then placed in a bath containing distilled water at room temperature. After 1, 3, 5, 7, 9, and $11 \mathrm{~h}$, the samples were removed from distilled water and weighed. The water absorption capability (WAC) was calculated with the equation below [10]:

$$
\text { WAC } \%=\frac{\mathrm{w}_{\text {wet }}-\mathrm{W}_{\mathrm{dry}}}{\mathrm{W}_{\mathrm{dry}}} \times 100
$$

where, $\mathrm{W}_{\text {wet }}$ represents the weight of the wet specimen and $W_{\text {dry }}$ represents the weight of the dry specimen.

\subsection{Enzyme Degradation Test}

Enzyme degradation test of the films were carried out as described by Zahra et al. [11] with slight 
modifications. The enzymatic reaction mixture, comprising $1 \mathrm{ml}$ of $\alpha$-amylase and cellulase and 25 $\mathrm{ml}$ of $0.1 \mathrm{M}$ acetate buffer, was placed in clean beaker. The dried samples of the films were cut into $3 \times 3 \mathrm{~cm}^{2}$ specimens, weighed, and immersed in the beaker. After 1, 3, 5, 7, 9 and $11 \mathrm{~h}$, the samples were removed, rinsed with distilled water to remove the enzyme, dried, and weighed, respectively. The DED (Degree of enzymatic degradation) was calculated using the Eq. (4) [12]:

$$
\operatorname{DED}(\%)=\frac{\mathrm{w}_{0}-\mathrm{w}_{\mathrm{d}}}{\mathrm{w}_{\mathrm{d}}} \times 100
$$

where, $\mathrm{W}_{0}$ and $\mathrm{W}_{\mathrm{d}}$ represent the initial and final weights (before and after degradation, respectively) of the blends.

\subsection{Detection of Reducing Sugars}

Reducing sugars in degradation solutions were quantified by the dinitrosalicylic acid (DNS) method [13]. DNS $(1 \mathrm{ml})$ was added to $1 \mathrm{ml}$ of the sample to be analysed using $1 \mathrm{mg} / \mathrm{ml}$ glucose stock solution as a standard. The blank was prepared using 1 $\mathrm{ml}$ of control sample. The mixture was heated at 90-100 ${ }^{\circ} \mathrm{C}$ for $10 \mathrm{~min}$, cooled to room temperature, then $5 \mathrm{ml}$ of distilled water was added, and the absorbance at $540 \mathrm{~nm}$ was measured. The respective carbohydrate concentrations were obtained by comparison with a standard curve.

\subsection{Soil Burial Test}

Soil burial test was performed on the films according to the method of described by Thakore et al [14]. The films were buried in compost soil that was purchased from a flower nursery; Two different pots were filled to their approximate capacity of $10 \mathrm{~L}$ with soil and compost. The samples were cut into $30 \times 50$ $\mathrm{mm}^{2}$ pieces and buried in the soil at a depth of $10 \mathrm{~cm}$. The soil was placed in the laboratory, and the moisture of the soil was maintained by sprinkling water at regular time intervals. Excess water was drained through a hole at the bottom of the pot. The degradation of the samples were determined at regular time intervals (7 days) by carefully removing the sample from the soil and washing it gently with distilled water to remove soil from the film. The sample was dried under vacuum until a constant weight was obtained. Weight loss of the sample over time was used to indicate the degradation rate of the soil burial test. The soil burial test was studied by evaluating the weight loss of the film over time. The weight loss was determined every seven days from the starting day, and was calculated using the equation below:

$$
\text { Weight loss }(\%)=\frac{\mathrm{w}_{\mathrm{i}}}{\mathrm{w}_{\mathrm{d}}} \times 100
$$

where, $W_{d}$ is the dry weight of the film after being washed with distilled water and $\mathrm{W}_{\mathrm{i}}$ is the initial dry weight of the specimen.

\section{Results and Discussion}

The $\mathrm{pH}$, percentage acetylation/carboxylation and DS of modified and native starches are shown in Table 1.

The $\mathrm{pH}$ values of the chemically modified starches (5.52, 5.15, 5.38 for starch acetate, starch citrate and starch mixture respectively) were significantly lower $(P>0.05)$ than that of the native starch (7.43) due to the reaction of starch with acetic anhydride and citric acid. These starches falls within the $\mathrm{pH}$ range obtained for most starches employed in the food, cosmetics and pharmaceutical industries therefore,

Table 1 Physicochemical properties native and modified starch.

\begin{tabular}{lllll}
\hline Parameters & Native starch & Starch acetate & Starch citrate & Mixture \\
\hline PH & $7.43^{\mathrm{a}}$ & $5.52^{\mathrm{b}}$ & $5.15^{\mathrm{d}}$ & $5.38^{\mathrm{c}}$ \\
\% Acetylation/Carboxylation & $0.000^{\mathrm{d}}$ & $13.76 \pm 0.03^{\mathrm{a}}$ & $1.72 \pm 0.020^{\mathrm{c}}$ & $11.80 \pm 0.02^{\mathrm{b}}$ \\
Degree of substitution & $0.00^{\mathrm{d}}$ & $0.599 \pm 0.002^{\mathrm{a}}$ & $0.066 \pm 0.001^{\mathrm{c}}$ & $0.473 \pm 0.001^{\mathrm{b}}$ \\
\hline
\end{tabular}

Within rows, values with different letters (superscripts) are statistically different at $\mathrm{P}<0.05$. Each data is mean \pm SD of three replicates. 
they may be employed in the food, pharmaceutical, and cosmetics industries [15]. This result is consistent with that of Omojola et al. [16] and Nnemeka et al. [17] who also obtained a $\mathrm{pH}$ value of 4.59 for Icacina starch citrate $[16,17]$

Result also showed that the modified starches are significantly substituted with acetyl group and carboxyl group compared to the native starch. Even though, the Food and Drugs Administration of the United States (FDA), Food and Agriculture Organisation (FAO) and Ricón, Rached, Aragoza \& Padilla stated that the maximum acetyl content allowed for food starches utilization in food industry is $2.5 \%[18,19]$. The value obtained for the acetylated cassava starch in this study is higher than $2.5 \%$ thus; it is not suitable for use in the food industry (FDA) but can be used as packaging material. The high values obtained are similar to those reported for acetylated banana starch [20], barley starch [21], corn starch [7], maize starch [22], oat starch 23], pea starch and chick-pea starch [21].

\subsection{Water Absorption Capacity (WAC)}

The effect of starch modification on water absorption capacities of the films is shown in Fig. 1. Result from this study showed that the water absorption capacity of modified starch films were significantly $(p>0.05)$ lowered compared to that of TPS (negative control) and native starch film (positive control). Result also showed that the water absorption capacity varied among the modified starches with starch citrate being lowest.

Modification led to decrease in both weight loss and water uptake. Modification decreased the water solubility of films because the modifiers (acetic anhydride and citric acid) act as a barrier against the diffusion of the water to films. Low water uptake/absorption in the modified starch films can be explained in terms of changes in molecular structure of the starch. A cross-link network is formed in the starch molecules when hydroxyl group (OH) is replaced with acetyl and carboxyl groups, which inhibit the absorption of water as these groups are less hydrophilic than the $\mathrm{OH}$ group [24]. This result is similar to that of Khan et al. [25], Lawal [22], Michelle [24], Taghizedeh et al. [26] and Abbasi [27] who also observed low water absorption capacities for modified corn, cocoyam, and tapioca starches. Since most of the former packaging films made out of starch are not suitable for packaging because they absorb water easily, acetic anhydride and citric acid modified cassava starch may be used because water absorption is reduced.

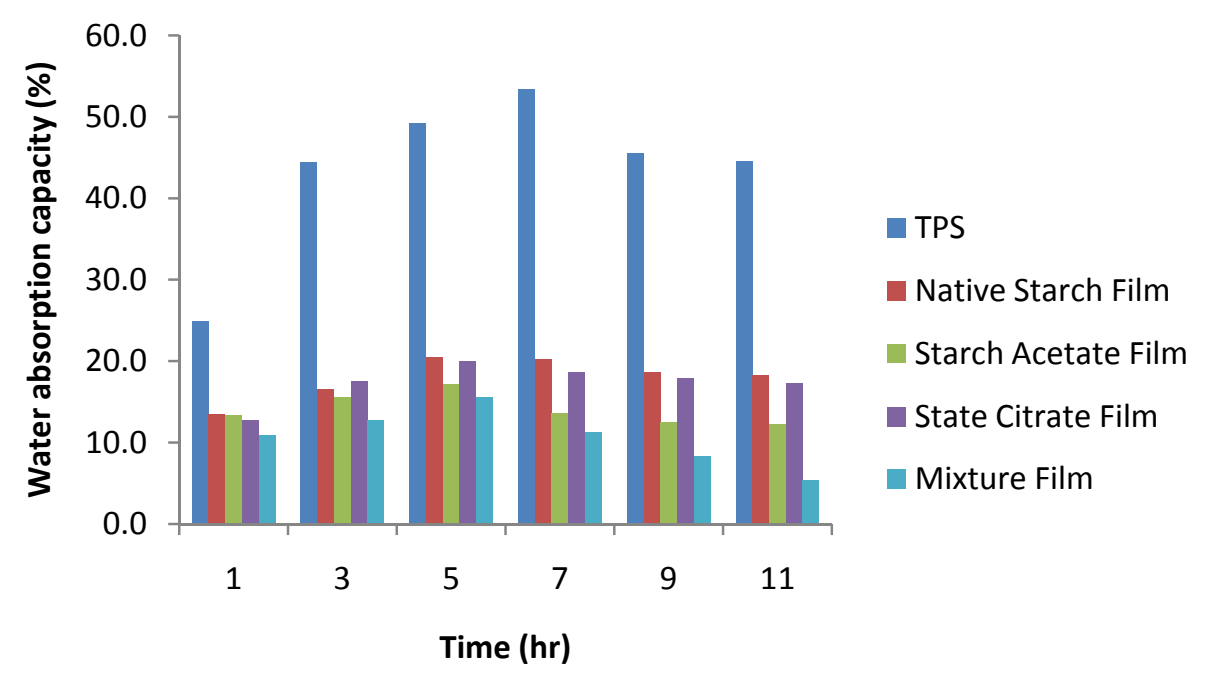

Fig. 1 Water absorption capacity of TPS, modified and native starch films. 
5. Degree of Enzyme Degradation (DED) and Yield of Reducing Sugar Using DNS Method

The effect of starch modification on the degree of enzymatic degradation of the various films and their release of reducing sugar (glucose) are presented in Figs. 2 and 3. The result showed that enzyme degradation of the films is significantly different from one another. Degradation is most rapid in native starch films especially pure TPS film and slower in modified films with starch mixture being the slowest.

Amylase attacks the bonds faster than the modified and native starch films such that about $95.87 \%$ weight loss was observed after 9 hours of immersion in enzymatic solution. On the other hand, weight losses of $98.61 \%, 95.99 \%, 95.81 \%$ and $95.94 \%$ were observed for native, acetylated, carboxylated and mixture starch films respectively after 11 hours.

The result also showed that the rate of glucose production was most rapid for the native starch films

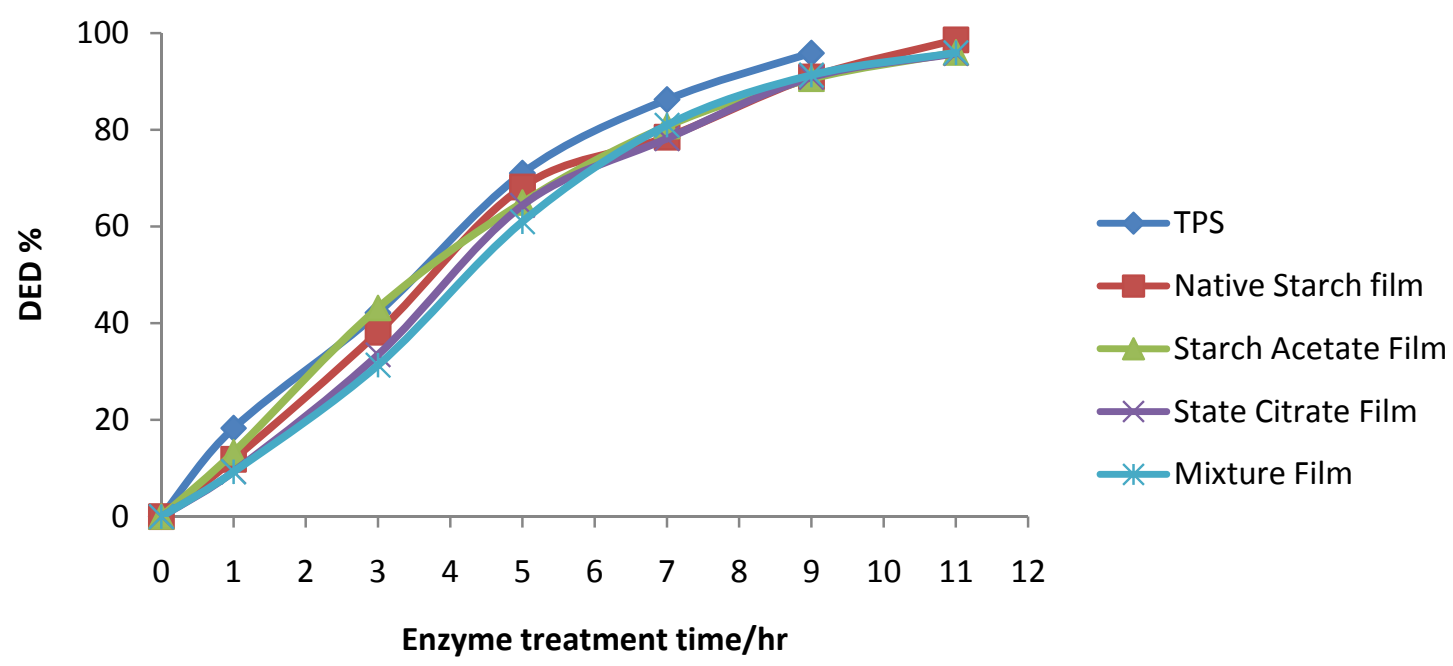

Fig. 2 Enzymatic degradation of TPS, modified and native starch films.

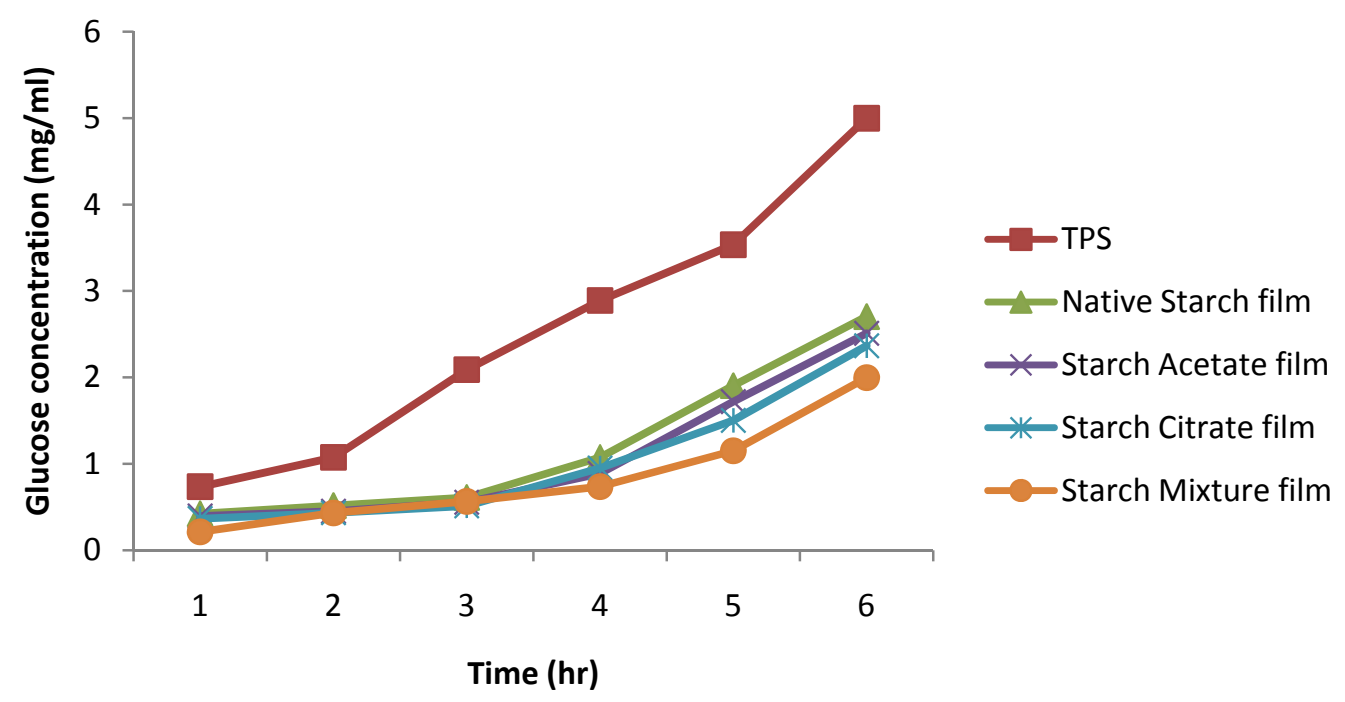

Fig. 3 Concentration of glucose produced for modified and native starch films in the first $6 \mathrm{~h}$ of enzymatic degradation due to the action of $\alpha$-amylase and cellulase. 
particularly TPS. However, the modified starch films showed a very much decrease in glucose production such that the amount of glucose produced after 6 hours of immersion into the enzymatic solution were; $4.998 \mathrm{mg} / \mathrm{ml}, 2.705 \mathrm{mg} / \mathrm{ml}, 2.511 \mathrm{mg} / \mathrm{ml}, 2.366 \mathrm{mg} / \mathrm{ml}$ and $1.997 \mathrm{mg} / \mathrm{ml}$ for TPS, native, starch acetate, starch citrate and starch mixture films respectively; showing the same trend as in enzymatic degradation.

Natural starch is known to be hydrophilic as a result of the free $\mathrm{OH}$ group in its structure. The substitution of this group with acetyl and carboxyl groups increases cross linking of the starch, decreases the hydrophilicity thus, stabilizes and slows degradation of the films.

The branched chains are attacked by glucoamylases. This is because $\alpha$-amylases are endoamylases, which speed up the hydrolysis of the internal $\alpha-1$, 4-glucosidic linkage in the starch in a random manner. These enzymes break down the starch into smaller sugar units, which in the end are converted to the basic glucose units. Because acetic anhydride and citric acid have replaced some of the $\alpha-1,6$ glycosidic bonds and make them unavailable for amylase activities, amylase action is reduced thereby accounting for the slowness of the film. Hence the hydrolysis of the cassava starch films weakened the interaction between cassava starch alone as is the case of TPS and cassava starch and the fillers as is the case of modified and native starch nanocomposite films thereby resulting to higher weight loss by the TPS film after just 5 hours of immersion into the enzymatic solution followed by that of the native starch nanocomposite film and then the modified starch nanocomposite films. This result is similar to that of Azahari et al. [28] and Zahra et al [11].

\section{Soil Burial Test}

The result in Fig. 4 shows the effect of starch modification on the weight loss of starch films in the compost soil against time. The result revealed that the weight losses varied among the films with modified starch films having the least weight loss and slowest rate of degradation compared to TPS and native starch films. About $98.11 \%$ of TPS film degraded in compost soil in 96 hours of the study. Next is native starch film with degradation rate of $97.37 \%$ in compost soil in about $120 \mathrm{~h}$ of the study. The modified starch films however, degraded in $144 \mathrm{~h}$ with starch mixture film having the least degradation rate (97.09\%, 96.29\% and $95.93 \%$ for starch acetate film, starch citrate

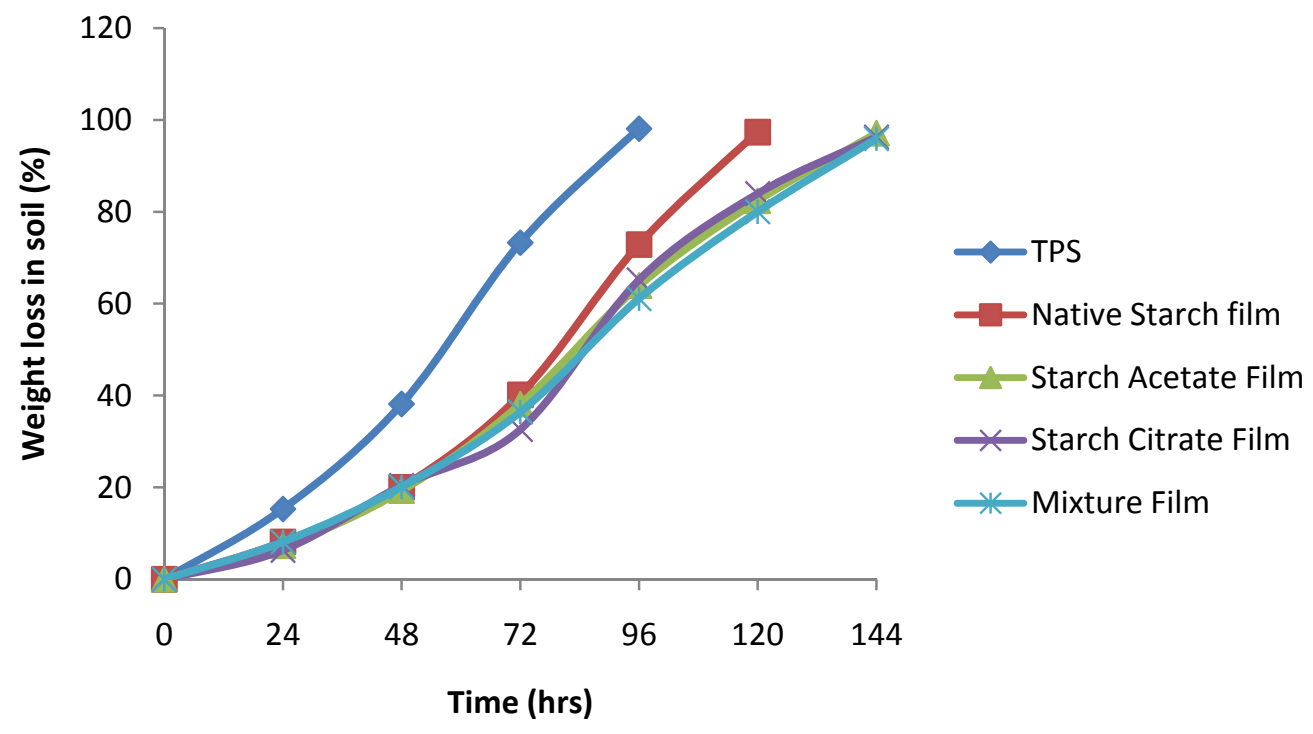

Fig. 4 Weight loss of TPS, modified and native starch films after $144 \mathrm{~h}$ in soil. 
film and starch mixture film respectively). The weight loss of the modified starch films during composting in this study clearly showed that the modified starch films are biodegradable. However, the weight losses of the modified starch films are slower than TPS and native starch film suggesting that the biodegradability of the modified starch films is lower than native starch film. This result is similar to Lin [29] who reported that the degradation rate of native corn starch is faster than that of modified corn starches. It therefore further shows that the acetic anhydride and citric acid improves the strength of the films leading to slower degradation in the compost soils. However, that these modified starches have increased strength and biodegradation means that it could be a good alternative to synthetic packaging materials used in most developing world.

\section{Conclusions}

The present study showed that modification with acetic anhydride and citric acid lowered the water absorption capacities of cassava starch films thus, slowing down their degradation rates but not affecting their overall biodegradability. Therefore, the modified starch films with acetic anhydride and citric acid may substitute the non-biodegradable polyethylene mulch film that is seen as a significant environmental pollutant.

\section{Reference}

[1] Chiellini, E. and Solaro, R. 1996. "Biodegradable Polymeric Materials.” Advanced Materials 4: 305-13.

[2] Araújo, M. A., Cunha, A. and Mota, M. 2004. "Enzymatic Degradation of Starch-Based Thermoplastic Compounds Used in Protheses: Identification of the Degradation Products in Solution.” Biomaterials 25: 2687-93.

[3] Gonera, A. and Cornillon, P. 2002. "Gelatinization of Starch/Gum/Sugarsystem Studied by Using DSC, NMR and CSLM." Starch/Starke 54: 508-16.

[4] Zhang, J. F. and Sun, X. Z. 2004. "Mechanical Properties of PLA/Starch Composites Compatibilized by Maleic Anhydride." Biomacromolecules 5: 1446-51.

[5] Bledzki, A. K. and Gassan, J. 1999. "Composites Reinforced with Cellulose Based Fibres." Progress in Polymer Science 24: 221-74.
[6] Torres, E. G. and Cubillas, M. L. 2005. "Study of the Interfacial Properties of Natural Fiber Reinforced Polyethylene." Polymer. Test. 24: 694.

[7] Aning, A. 2012. "Preparation and Characterisation of Acetylated Corn Starches." International Journal of Chemical Engineering and Applications 3 (3): 156-9.

[8] Chowdary, K. P. R. and Enturi, V. 2011. "Preparation, Characterization and Evaluation of Starch Citrate - A New Modified Starch as a Disintegrant in Tablet Formulations." International Journal of Pharmacy, Research and Development 12 (2): 9-17.

[9] Veerreddy, K., Kumar, T. P., Sandeep, B. and Kumar, D. S. 2012. "Comparative Evaluation of Modified Starches in Different Tablet Formulations as Disintegrants Der." Pharmacia Lettre 4 (6): 1680-4.

[10] Lei, Y., Wu, Q., Yao, F. and Xu, Y. 2007. "Preparation and Properties of Recycled HDPE/Natural Fiber Composites." Composites Part A: Applied Science and Manufacturing 38: 1664-74.

[11] Zahra, A. Omolbanin, A. and Farzaneh, M. 2013. "Enzymatic Degradation of Nanocomposites Carboxymethyl Cellulose and Poly ( $\varepsilon$-Caprolactone) and Containing Sodium Montmorillonite Clay by Cellulase." Journal of Applied Environmental and Biological Sciences 3 (8):1-6.

[12] Guohua, Z., Ya, L., Cuilan, F., Min, Z., Caiqiong, Z. and Zongdao, C. 2006. "Water Resistance, Mechanical Properties and Biodegradability of Methylated-Cornstarch/Poly (Vinyl Alcohol) Blend Film, Polymer Degradation and Stability." Polymer Degradation Stability 91 (4): 703-11.

[13] Miller, G. L. 1959. "Use of Dinitrosalicylic Acid Reagent for Determination of Reducingsugar. Analytical Chemistry 3: 426.

[14] Thakore, I. M., Desai, S., Sarawade, B. D. and Devi, S. 2001. "Studies on Biodegradability, Morphology and Thermomechanical Properties of LDPE/Modified Starch Blends." European Polymer Journal 37 (1): 151-60.

[15] Coursey, D. G. and Rasper, V. 1967. "Properties of Starches of Some West African Yams." Journal of Food Science and Agriculture 18: 240-8.

[16] Omojola, M. O., Orishadipe, A. T., Afolayan, M. O., Adebiyi and Adedayo, B. 2012. "Preparation and Physicochemical Characterization of Icacina Starch Citrate - A Potential Pharmaceutical/Industrial Starch.” Agriculture and Biology Journal of North America 3 (1): 11-6.

[17] Nnemeka, E. I., Omojola, M. O., Emeje, M. O. and Kunle, O. O. 2009. "Isolation and Evaluation of Some Physicochemical Properties of Parkia Biglobosa Starch." Pure Applied Chemistry 81: 97-104. 
Cassava starch Nanocomposite Films

[18] FAO. 2008. "Cassava in Food and Energy Security, Investing in Research in Order to Increase Yields and Uses.” FAO Newsroom, July 2008, Rome (Italy),

[19] Rincón, A. M., Rached, B. L., Aragoza, L. E. and Padilla, F. 2007. "Effect of Acetylation and Oxidation on Some Properties of Breadfruit (Artocarpus Altilis) Seed Starch. Archivos Latinoamericanos de Nutrición 57 (3): 287-94.

[20] Bello-Pérez, L. A., Contreras-Ramos, S. M., Jìmenez-Aparicio, A. and Paredes-López, O. 2000. "Acetylation and Characterization of Banana (Musa Paradisiaca) Starch.” Acta Cientifica Venezolana 51 (3):143-9.

[21] Francisco, P. G., Judith, P. M., María, A. M. M., Luis, A. B. P. and Alma, D. R. G. 2012. "Modification and Chemical Characterization of Barley Starch." International Journal of Applied Science and Technology 2 (4): 30-9.

[22] Lawal, O. S. 2004. "Succinyl and Acetyl Starch Derivatives of a Hybrid Maize: Physicochemical Characteristics and Retrogradation Properties Monitored by Differential Scanning Calorimetry." Carbohydrate Research 339: 2673-82.

[23] Mirmoghtadaie, L., Kadivar, M. and Shahedi, M. 2009. "Effects of Cross-Linking and Acetylation on Oat Starch Properties." Food Chemistry 116: 709-13.

[24] Michelle, L. H. 2013. "Development of Citric Acid
Cross-Linked Starch for Controlled-release Fertilizer (CRF)." Department of Chemical Engineering, Universiti Teknolog i P E TRONAS, Tronoh, Perak.

[25] Khan, K. H., Ali, T. M. and Hasnain, A. 2014. "Effect of Chemical Modifications on the Functional and Rheological Properties of Potato (Solanumtuberosum) Starches." Journal of Animal \& Plant Sciences 24 (2): 550-5.

[26] Taghizedeh, M. T., Abbasi, Z. and Nasrolahzadeh, Z. 2012. "Study of Enzymatic Degradationand Water Absorption of Nanocomposites Starch/ Polyvinyl Alcohol Andsodium Montmorillonite Clay." Journal of Taiwan Institute of Chemical and Engineering 43: 120.

[27] Abbasi, Z. 2012. "Water Resistance, Weight Loss and Enzymatic Degradation of Blends Starch/Polyvinyl Alcohol Containing SiO2 Nanoparticle." Journal of Taiwan Institute of Chemical and Engineering 43: 264.

[28] Azahari, N. A., Othman, N. and Ismail, H. 2011. "Biodegradation Studies of Polyvinyl Alcohol/Corn Starch Blend Films in Solid and Solution Media." Journal of Physical Science 22 (2): 15-31.

[29] Lin, S. 2010. "Chemical Modification of Starch and Preparation of Starch-Based Nanocomposites." A dissertation presented to the faculty of the University of Akron. In partial fulfilment of the requirements for the degree of Doctor of philosophy. 72-75. 